\title{
Contesting Space and Power through Digital Drama Research: Colonial Histories, Postcolonial Interrogations
}

\begin{abstract}
Video is increasingly used in qualitative research. This paper addresses some of the pedagogical, aesthetic, social, and ethical implications of using digital video in research of high school drama classrooms. How does the video medium produce particular spaces of representation and representations of space, and what are the implications when this medium is used in 'live' drama contexts? Video is a complex medium; it has come to represent both a vehicle and product of popular culture. This paper examines particularly how the gaze of video has historically affected and continues to shape the study and expression of human subjects, and concludes with suggestions about how digital and live drama modes might interact in synergistic ways that challenge normative modes of video production, drama practices, and the research encounter. Throughout, we use human geography, post-colonial, film, and feminist theoretical lenses to, as Trinh T. Minh-ha (1991)would put it, 'evoke' rather than 'explain' what a postcolonial digital drama might be.
\end{abstract}




\section{Contesting Space and Power through Digital Drama Research: \\ Colonial Histories, Postcolonial Interrogations ${ }^{1}$}

\section{Photography, Film, Video and Colonialism's Gaze}

The camera's gaze seems presently, in Western contexts, to be associated with various forms of social control, as we see in the pervasive use of video surveillance cameras (see Gallagher and Fusco 2006) in schools and beyond, ostensibly for "our" own protection. Photography, like many successive media technologies, was first developed, however, for scientific and technological purposes. The technological breakthroughs that led to cinema, for example, were made by scientists Muybridge and Marey, who were trying to analyse movement that escaped the naked eye (Darley 2000). Cameras have also, historically, been used in very colonizing ways in the work of early anthropologists, settlers, and artists trying to 'capture' the 'natives' on film for the pleasure of audiences back home. Félix-Louis Regnault, a physician specializing in pathological anatomy who became interested in anthropology (de Brigard 1995), was, in 1895, the first person to make an ethnographic film. In North America, the early work of film artist Robert Flaherty, and visual anthropologists Margaret Mead and Gregory Bateson (1942), developed further interest in the use of photography and film to research and present ethnographic data, which led to the emergence of the field of Visual Anthropology, now 30 years old. What has been somewhat controversially termed, 'Salvage Anthropology'

\footnotetext{
${ }^{1}$ The work represented in this paper is based on both Dr. Kathleen Gallagher's ethnographic study, Drama, Education, Youth \& Social Cohesion: (re)constructing identities in urban contexts for which Isabelle Kim was a graduate assistant from 20042006 and on Isabelle Kim's Masters' (2003) and current doctoral research on publiclyfunded, community-based youth videmaking projects in Ontario, Canada.
} 
(de Brigard 1995) also uses video and other media to 'salvage' 'dying' cultures by creating lasting audio-visual records.

A cursory look at the lexicon of photography further exemplifies its colonial roots: 'white balance', a 'take', 'shooting', 'capturing'. There are positions of power related to being 'in front of' or 'behind' the camera; of being 'photogenic' or not, of the tone of one's skin. Camera technology, and film in particular, favours the appearance of white skin. 'White balance', in technical terms, remains the default mode to which cameras are set and, in theoretical terms, the default mode to which the researcher's eye has become adjusted. Postcolonial theory, providentially, has helped to push the discussion of culture, identity, race, and art beyond essentialism and the celebration of 'multiculturalism' into more critical, complex, and hybrid terrain (Gallagher \& Rivière, 2004). Postcolonial writers and critics such as Edward Said (1979), Trinh T. Minh-ha (1991), Homi Bhabha (1994), Stuart Hall (1990) and Gyatri Spivak (1987) “argue... that culture and identity are the products of human encounters, the inventories of crosscultural appropriation and hybridity, not the elaboration of the ancestral essence of particular groups" (cited in Matus \& McCarthy 2003, p. 77).

This growing body of postcolonial literature has been, more recently, complemented by 'exilic' and 'diasporic' cinema (Naficy, 2001). These auteurs have shed light on the long-term and far-reaching influences of colonisation that continue to be experienced today:

'colonisation' is not simply a matter of economic/political dimension but also a problem of cultural/psychological dimension. The result is pervasive "otherness", 
that is, alienation from oneself, looking at oneself from the perspective of other people" (Cho, 1994, p. 22, cited in Jeong, 2001, p.129).

What could be more alienating than looking at oneself through the looking-glass of mainstream media to see only constructed images masquerading as one's reflection? Diasporic film and video festivals, such as the Toronto Reel Asian International Film Festival, have emerged to showcase works that explore the politics of representation and challenge the colonial gaze of mainstream media. A growing proportion of this work is made by youth.

Walter Benjamin (c1997) argued that in order to prevent politics from becoming aestheticized, aesthetics needed to become politicized. From our perspective, it is not enough, therefore, to simply show marginalized identities from a postcolonial point of view but the very mode of production and reception of film/video needs to be radicalized. Over the last thirty years, the impact of video technology on social and cultural movements has been enormous, as has the 'social' impacted upon the development and uses of video technology. For instance, organizations for social change have tried to radicalize the production and reception of film and video. Greenpeace and other activist groups use video cameras to document, portray and make public particular issues that pass under the mainstream radar. Most recently, in the format of webcams and vlogs (video logs), and machimina ${ }^{2}$, digital video technology has been used to make political statements, and to make the personal public on the World Wide Web.

\footnotetext{
${ }^{2}$ Machimina is "a form of film-making that uses video-game software to tell stories". Alex Chan posted his machimina film "The French Democracy" (2006), inspired by the French riots (fall 2005) online. The story was picked up by The Washington Post and
} 


\section{The Digital Video Camera as Research Eye in the Drama Classroom}

For the production of video work, we have found that the drama classroom provides a fertile space. On a very basic level, the open space of the drama classroom lends itself to videomaking, an activity that requires freedom of movement. In Gallagher's ethnographic research in urban drama classrooms in New York City and Toronto ${ }^{3}$, students in both cities identified the open space in the drama classroom as playing a major role in enabling the kinds of social relationships and work made possible in drama, compared to other classes that were more traditionally set up with desk and chairs (Gallagher 2007 in press), As Sanjeet, a South Asian, first-generation Canadian, grade twelve student in one Toronto school explained:

The drama classroom plays a huge role. Again, if it was drama but we all sat in straight rows and desks, we wouldn't interact as much, but, um, it's very open. And maybe it's a reflection of what the class does to you inside. It opens you up, just like the open space, um, yeah... And it's conducive to, um, discussions, like when we sit around in a circle, you see everybody and you can make eye contact and, you know, people are nodding their heads so you know when you say something, they agree with you. Whereas if someone behind you agrees, you have no idea.

interest quickly spread around the world. Chan's film was recently screened at the Worldwide Short Film Festival on June 14, 2006, in Toronto. Chan used the PC software recently released by Lionhead Studios called "The Movies", which provides novices with a full set of filmmaking tools and an easy system for posting the results on-line". (Colbourne, The Globe \& Mail, June 14, 2006, R1-R2).

\footnotetext{
${ }^{3}$ The 3-year ethnography took place in four urban high school drama classrooms, two in Toronto, Canada and two in New York City, USA. The research was funded by the Social Sciences and Humanities Research Council of Canada.
} 
But, significantly, as one drama teacher in a Toronto school noted:

Drama's not an automatically... you know, safe and respectful and community space. You have to really work hard to achieve that, both as a teacher and as a class.

To be sure, the drama classroom is a space that can be more permissive of the distinctive expressions and contributions of young people, a space in which speaking out of turn is the norm; a space that is the crossroads of students' performances as "students"- socially positioned by gender, race, class, ability, sexuality, as they are- and as artists, young people improvising performances and identities out of thin air. The drama classroom, in our experience, can open up spaces for both imaginary and real border-crossings.

In the context of our research, we often videotaped the live performances and discussions that occurred in the drama classrooms. Not wanting to assume that the presence of a video camera would be seen as benign by the students in the classrooms, we asked them to anonymously respond to the question: what was it like for you to have a video camera in your drama classroom. Their responses gave us pause "I didn't move towards it at all, but I didn't move away from it either. I just accepted it being there. It was kind of making me feel nervous whenever I was videotaped. But I was ok with it when I was told to talk to the camera as if it was an interviewer. But I didn't like it being around when I was working in groups. It kind of added more intimidation because everything that comes out of your mouth in group work is just off the top of your head. So I felt a little vulnerable when that happened." 
"Our performance was video-taped. While it was taped I felt as though it was another individual in the room. I felt it was like a completely different person, one who I didn't know. It felt strange at first, but as we went on I no longer noticed its presence; it was like it disappeared".

"When the camera was in the classroom I really didn't care. I didn't want to be on camera, but I didn't care if I was. My monologue performance was not videotaped and I'm happy about that. If I memorized my lines then I would love to have it taped 'cause I looked cute that day."

"With the camera situation, I didn't feel shy or insecure when it was on me because to tell the truth I like the camera and I don't mind being in the spotlight." These responses speak to the point made in an essay Walter Benjamin (1997) wrote comparing film and theatre. He noted that when a performance is recorded/mediatised, the public becomes an 'expert' or impersonal judge. The camera is the critic. When the camera is perceived as a judgemental critic, the attitude of the viewer, then, becomes one of testing; s/he tests. Not surprisingly, film actors' auditions include 'screen tests'. The presence of the camera is clearly different from the presence of other live people in drama, with whom or for whom one is performing. In recent years, many efforts have been made in post-positivist qualitative research to minimize the impact of the critical eye cast upon research 'subjects'; it is crucial, therefore, that those of us interested in using this potentially objectifying tool, think seriously about how to change the terms of communication with the camera, in order to extend rather than inhibit our relationships with research participants.

\section{Some Aesthetic Considerations}


French-Canadian playwright/actor/director Robert Lepage (in Delgado and Heritage 1996) likens the "live" experience of theatre to a sporting event. People scream and shout at a sporting event because they believe it may change the course of things. In theatre too, he says, people want to believe that they are somehow changing the event, that their presence is changing the course of things (p. 146); theatre does not "fix", like an image or a word captured by the truth-telling camera. A challenge for drama educators, then, who use video in their practice or their research, is to negotiate pedagogical spaces in which students/research participants are not merely testing and being tested/criticized by the lens but contesting and returning the gaze. Another of our research participants was particularly eloquent on this point:

I felt okay about my performance being videotaped. I didn't realize I would be videotaped until I got on stage and began my monologue. When I saw it, it threw me off a bit. From that point forward, I avoided looking into the camera because I felt it isolated me, and was like a critic, waiting for me to fumble. I found looking at audience members a lot more effective. In their faces, I could see their reaction to my words, and find the incentive to deliver my lines as best as possible. So, in conclusion, I would say that I did not want to be videotaped. However, I didn't dislike it enough to request not to be videotaped.

Robert Lepage extends his metaphor further when, in a 1996 interview, he talked about theatre being a vertical form of art rather than a horizontal form like film or television, explaining:

It's vertical on many levels in the sense that I think theatre has a lot to do with putting people in contact with the gods, whatever that means. That's where 
theatre comes from. Plays were written in a vertical manner about human aspirations... There is a sense of spirituality in theatre: it's a medium that you could use to talk about spirituality, about spiritual quests. Of course, there's a reason why film has a horizontal frame; because cameras pan and cinema is all about everyday life and realism. Being at that level it goes from left to right, or right to left. Sometimes it does pan up and down, but in general horizontal stories are better told with film. Maybe the shape and frames of film will all change one day. But why hasn't anybody invented a vertical screen after a century of cinema? The medium technically and symbolically is about the horizon, the land on which human beings work and walk (144).

While we have yet to see a vertical screen, video artists are taking up Lepage's aesthetic challenge by creating and exhibiting their work in ways that push the traditional 'horizontal' boundary of film.

Extending further this aesthetic metaphor, Lepage suggests that there are two ways to tell a story: a metaphorical way and a metonymical way. Metonymy is a horizontal telling - a beginning, middle and end - with things happening in a certain order. But metaphorical telling is like seeing a piece of theatre where there are many levels, where things seem to be connected in a "vertical way". One of our questions, therefore, if we take Lepage's analysis as significant, is to consider how the vertical work (ie drama pedagogy) of theatre can be deepened by, and not simply captured by, the "horizontal medium" of video. In short, what can be made of the intersection of these "vertical" and "horizontal" forms of artistic expression? 
To extend these aesthetic ideas to the realm of research, one must also then ask what the substantive and artistic implications are for postmodern, postcolonial, critical, messy, fragmented, and "vertical" forms of research reporting? With the increasing use of video in many forms of qualitative research, it will become even more important to understand the aesthetic, epistemological, and substantive impact of the camera on research relations and knowledge production. Lepage is arguing that film is very 'personal', very 'private'; it goes with the medium of close-ups, the things you don't normally see. Whereas theatre, he insists, is where the sources of inspiration are the people who are there with you, the ones who 'help you out'. He states:

The idea of theatre is first of all to bring people in a dark room and do the festival of light. Of course the fire of these [early] theatres was replaced by technology, by electricity, but people still come to the theatre to sit around the fire (p. 157).

The implications for knowledge production and collaborative research are significant. If we aim to use cameras in our drama classrooms for artistic and research purposes- and we are arguing here that we should expand our repertoire of modes of working and researching in drama classrooms- then we must take seriously these metaphysical quandaries about the relationship of people to each other when that relationship is mediated digitally.

\section{Towards a Digital Drama}

The concept of 'multi-arts' activity offers a useful starting point to consider how these two separate yet complementary live and digital dramatic forms can be used synergistically in drama education and research. According to the Ontario Arts Council (OAC), a provincial governmental arts-funding organization: 
Multi-arts activities are artistic works, practices and events that use two or more

artistic disciplines in co-existence, with each discipline retaining its own identity

in the creation, production and presentation of the artistic work.

(http://www.arts.on.ca)

If we conceive of 'digital drama' as a 'multi-arts activity', a synergy between the two disciplines of drama and video art, in which the sum is greater than its constituent parts, 'digital drama' needs to be more than videotaped drama activities. The common uses of video in drama tend to render drama flat and these methods often exploit only the recording capacities of video; they treat video as a technical tool rather than an artistic medium.

A video or film is more than recorded theatre and theatre is more than simply the content of film. Video, for instance, might be used simply and aesthetically to create digital versions of 'tableau' that could be shown on one or multiple screens as backdrop for live drama performances. In this example, the horizontal screen is in a dialectical and spatial relationship with the live drama. Another possible and more complex digital drama practice might include live drama performances that are simultaneously videotaped from multiple points of view. The videos would be viewed collectively and each student performer could then edit a version of each performance for a Rashomon ${ }^{4}$ effect and analysis. This exercise might stimulate and deepen performances and analysis of the (role)play as well as create innovative ways of integrating individual with groupbased directing and editing practices. These are but a few examples of the potential

\footnotetext{
4 "Rashomon" has become a code word for the multiplicity/relativity/unattainability of truth. "Rashomon" is the title of a film by the illustrious Japanese filmmaker Akiro Kurosawa (1950). The film examines a tale of rape and murder from four different perspectives. (Summer 2006 Programme Guide, Cinématheque Ontario, p.15).
} 
synergies between drama and video that might evoke an innovative, critical, and aesthetic digital drama.

Artistically and technically speaking, however, there are considerable differences between the two media. For instance, the nature of "point of view" (POV), as well as the ephemeral and live nature of drama versus the recordable/reproducible nature of video are among two of the more striking differences we have been considering. Camera devices such as extreme close-up or wide-angle lens can isolate subjects and make it possible to analyze and see in particular ways. The video camera seems also to favour a more intimate point of view. With video, the various points of view are created by the person controlling the camera, whereas in a live drama production the control is more diffused. The POV in live/improvised drama performance can be shifting and multiple. POV is also partially determined by where you are seated in the audience or positioned in the room in process drama forms. It is also dependent upon the players' performances at any given moment. As we know, no two live performances or process dramas are identical. On a meta-physical level, POV is, of course, much more complex and depends on a multitude of other factors including how one is positioned vis-à-vis the context, the content, and the characters in the performance.

Video is increasingly being used in drama classrooms and also in the publication of research, including electronic journal articles where clips are either embedded in written narratives or accessed through a hyperlink to video files (Pink 2001, p.164). What gets included and what gets excluded when we use a video camera to 'make' field notes? Do we focus on things with video that would not normally attract our attention? Our society is supersaturated with digital technology in which "information of every kind and 
for every purpose is now mostly in digital form" (Gere, 2002: 10), and yet, "empirically grounded, theorised knowledge of the full potential of digital technologies for qualitative research is still in its infancy.” (Dicks et al, 2006: 19). Further investigation is urgently needed, therefore, into the effects of incorporating media, such as video, as a method of data collection in schools.

\section{Implications for Digital Drama Research with Youth}

One possible way of addressing the full potential of digital video technology for qualitative research is to use video not only to portray but to create and analyze data spatially. Increasing attention is being paid to the relationships between space, learning, youth, and social relations (Mitchell 1994, 2002; Moje, 2004; Soja, 1996, 2004; Massey, 1998; Hull \& Katz, in-press; Hull \& James, in-press; Gallagher, 2007 in-press). In a society in which we not only capture images on video cameras but are captured by surveillance video cameras everyday, digital drama provides a space of possibilities for engaging with the media in critical, aesthetic, playful, and alternative ways.

Borrowing from Henri Lefebvre's conceptualization of space, we can consider any art-making space, including video and drama, as representations of space, and spaces of representation (Lefebvre 2000/1974). In Lefebvre's system of lived (representational spaces), perceived (conflict spatial practices), and conceived (representations of) space, it is "representation" that pervades all spatial experience (McGrath 2004). Conceived spaces are those created by architects and city planners; lived spaces are those inhabited by members of a community. Perceived spaces represent what inhabitants make of their lived spaces. Massey (1998) has argued that when thinking about youth culture in spatial terms: space is organized in terms of "a vast complexity of interconnections" (p.124). We 
might think about the connections that youth make between what they see in the media and the media (video)-making spaces they create in the drama classroom and elsewhere. For example, through "collective modes of production" (Halleck, 2002; Naficy 2001) that borrow from process drama, students can build on their 'live' drama practices and performances, to conceive, using video, representions of their 'lived' or hoped for/imagined spaces. Teachers and students can, as 'co-researchers', analyze these videos and create ethnographic performance texts (see Gallagher in press 2006) that can be performed live and/or recorded using video and other multi-media. These digitized performances can be further shared between different research sites, locally, internationally and via the World Wide Web. This mode of research can galvanize drama and media arts education, as well as qualitative research practices generally. Qualitative researchers have only recently begun exploring new media, hypertext, and webtechnologies to research and present their findings. As with any new research tool, however, the ethical issues are beginning to emerge and require further theorizing (see Dicks et al, 2005).

\section{Ethical Considerations and Unanswered Questions}

As the (colonial) history of photography/film has shown us, there are clearly ethical issues related to using video to 'show' and 'tell' research. These have primarily to do with both the ethics of representation of "Others" by dominant groups and with the reproducibility of digital technology. Live drama is ephemeral, but digitizing drama creates a record that can be altered and copied. Who gets to keep a copy of digital drama records? Who has a right to edit these? Where will the videos be shown and to whom? Who decides? Should ownership be collective and belong to the research participants and 
the researcher? What are, in short, the particular kinds of practices of inclusion and exclusion that can occur in digital drama contexts? We noticed in our own research that gendered, class, racial, linguistic, and other inequities become particularly foregrounded in digital, as opposed to live, drama modes. The visual mode and recording capacity of the camera intensifies issues of appearance, a particularly strong force of exclusion. Furthermore, because a video camera not only records but also produces a lasting recorded product, its presence tends to favour a more product-driven approach and process. Recall the student's earlier comment about not wanting her group process to be recorded. In other words, the permanent record of aesthetic processes could calcify those processes and impede creative experimentation.

Digital drama contexts seem also to intensify the kinds of inequities traditionally associated with gender and technology contexts. Teachers often comment that girls tend to be cast in administrative and performance roles, while boys more often find themselves in direction and production (editing, camera) roles. Issues of class and physical ability, too, are likely to figure more strongly in digital drama contexts. Students who have access to digital video equipment, and the physical skills required for filming, are more likely to be comfortable with the equipment, and therefore 'cast' in producer/editor/camera-person roles.

In our research with video and drama in one high school site, there seemed to be an initial paralysis when students tried to imagine different narratives and alternative ways of using video that challenge dominant power relationships. It was difficult to witness the performance of one group of female and male students of colour in a Toronto school, who performed a wholesale imitation of a 'Jerry Springer' daytime talk show, 
depicting both racial and sexual stereotypes. It was all the more disturbing when juxtaposed against the complex and critical nature of their live drama performances. But Bakhtin (1981) offers us a different way of thinking about this imitation process: "as parody, pastiche, intertextuality or dialogic communication-instead of merely imitation" (cited in Buckingham 2003, p.135). Imitation might indeed be a useful starting point for the critical examination of different media genres. As Bordo (2003) has rightly insisted, "simultaneously we can be both vulnerable and savvy to the empire of images" (cited in Stack and Kelly 2006, p. 9). Youth can simultaneously be critical of and enjoy watching and making media narratives that appear to be in direct conflict with who they are. It is dangerous to view youth narratives as "transparent... window[s] on youth's capacities, secrets, and problems" (Daiutte 2002, p.213). First attempts at videomaking are not necessarily reflections of the stories youth are most interested in. Many different takes, exposure to diverse genres, and time are needed to build the skills, confidence and relationships needed to 'risk' departing from mainstream genres and narratives.

The presence and influence of mainstream media looms large when a video camera is used to tell a story. The dominant genres, techniques, tropes and archetypes that are ubiquitous in mainstream television and film, like continuous editing, the voiceover narrative, and 'talking-heads', become generic patterns ingrained in the fabrication of digital stories. Mainstream media representations of identity and the way stories are told have come to colonize the imagination. The result is that students often approach videomaking with a priori expectations of what a video can and should look like, what kinds of stories are told on film/video and whose stories are told. For the research participants in one of our drama classrooms "making a video" seemed to focus primarily 
on creating a "good" end product. This is perhaps not surprising given the polished quality of mainstream film/video products that youth are regularly exposed to. One teacher, Ms. S, remarked that the videomaking process seemed to channel her students' energies and attention in a highly focused and formal way compared to the more informal and diffuse modus operandi of the live drama class.

And so we are left with some thought-provoking questions: Can digital drama create new spaces of representation that push beyond the narrow boundaries of the mainstream, dominant media representations that occupy our imagination, and especially the imaginations of children and youth? Can the interiority of role-playing or the sense of timelessness that often marks live drama enterprises be 'translated' to digital video modes? Can research that exploits digital modes of recording and representing avoid the pitfalls of the objectifying gaze of the camera? Can collaborative forms of research proliferate with the inventive use of video as a collective rather than a hierarchical artistic process? Can digital drama provoke new postcolonial research narratives? The questions remain largely unanswered, but what is certain is that a multi-arts mode of artistic expression has become both more possible and more desirable to many young people. How we harness those possibilities pedagogically remain to be seen. And reflection on how, significantly, we use new digital tools in our drama research specifically, and qualitative research more generally, moves us into uncharted territory, where both the enormous creative potential and the dangers of reductionism and colonization loom equally large. 


\section{References:}

Bakhtin, M. M. (1981). The Dialogic Imagination: Four Essays by M.M. Bakhtin. Austin: University of Texas Press.

Bateson, G., \& Mead, M. (1942). Balinese Character: A Photographic Analysis. New York: New York Academy of Sciences.

Benjamin, W. (c1997). Sur l'art et la photographie. Paris: Editions Carré.

Bhabha, H. (1994). The location of culture. London \& New York: Routledge.

Bordo, S. (2003). The empire of images in our world of bodies. Chronicle of Higher Education. B6-B9.

Buckingham, D. 2003. Media Education: literacy, learning and contemporary culture. Cambridge, UK: Polity Press.

Cho, H.-J. (1994). Reading Texts and Reading Lives in the Post-Colonial Era Vol. 2: Right Here, Where You Stand (partly translated by Oum, Journal of Gender Studies, Vol. 5, no. 3, November 1996, pp. 389-391, Trans.). Seoul: Alternative Culture Press (in Korean).

Colbourne, S. (2006, June 14, 2006). The films millions of gamers love. The Globe \& Mail, pp. 1-2.

Daiutte, C. (2000). The Narrative Sites for Youths' Construction of Social Consciousness. In L. Weis \& M. Fine (Eds.), Construction Sites: Excavating Race, Class, and Gender among Urban Youth. New York and London: Teachers College Press.

Darley, A. (2000). Visual Digital Culture: Surface Play \& Spectacle in New Media Genres. New York \& London: Routledge.

de Brigard, E. (1995). The History of Ethnographic Film. In P. Hockings (Ed.), 
Principles of Visual Anthropology (second ed.). Berlin \& New York: Mouton de Gruyter.

Delgado, M. and P. Heritage (eds.) Robert Lepage in conversation with Alison McAlpine at Le Café Du Monde, Quebec City, 17 February 1995. In In Contact with the Gods: Directors talk theatre. Manchester and New York: Manchester University Press.

Dicks, B., Mason, B., Coffey, A., \& Atkinson, P. (2005). Qualitative research and hypermedia: ethnography for the digital age. London \& Thousand Oaks, CA: Sage.

Dicks, B., Soyinka, B., \& Coffey, A. (2006). Multimodal Ethnography. Qualitative Research, 6(1), 77-96.

Gallagher, K., \& Riviere, D. (2004). Pink... with shades of grey: mediating moments of diversity in urban secondary classrooms. Westminster Studies in Education, 27(2), $127-141$.

Gallagher, K., \& Fusco, C. (2006). I.D.ology and the technologies of public (school) space: an ethnographic inquiry into the neo-liberal tactics of social (re)production. Ethnography and Education, 1(3), 301-318.

Gallagher, K. (in press 2006) Sexual Fundamentalism and Performances of Masculinity: an ethnographic scene study. International Journal of Gay and Lesbian Issues In Education. 4(1).

Gallagher, K. (in-press 2007). The Theatre of Urban: Youth and Schooling in Dangerous Times. Toronto, Buffalo, London: University of Toronto Press.

Gere, C. (2002). Digital Culture. London: Reaktion Books. 
Hall, S. (1990). Cultural identity and diaspora. In J. Rutherford (Ed.), Identity: community, culture, difference. London: Lawrence and Wishart.

Halleck, D.-D. (2002). Hand-Held Visions: The impossible possibilities of community media. New York: Fordham University Press.

Hull, G., \& James, M. (in press). Geographies of Hope: A Study of Urban Landscapes and a University-Community Collaborative. In P. O'Neill (Ed.), Blurring boundaries: Developing writers, researchers, and teachers: A tribute to William L. Smith.

Hull, G., \& Katz, M.-L. (in-press). Crafting an agentive self: Case studies on digital storytelling. In Research in the Teaching of English.

Jeong, H.-S. (2001). Theory, Practice and 'Empowerment' in Media Education: A Case Study of Critical Pedagogy. Unpublished doctoral, University of London, London.

Kim, I. (2003). The Critical Pedagogy of Youth Experiences with Drama and Videomaking (unpublished M.A. thesis). Unpublished Master's, University of Toronto, Toronto.

Lefebvre, H. (2000/1974). La Production de l'Espace, (fourth edition). Paris: Anthropos. Massey, D. (1998). The Spatial Construction of Youth Cultures. In T. Skelton \& G. Valentine (Eds.), Cool Places. New York \& London: Routledge.

Matus, C., \& McCarthy, C. (2003). The Triumph of Multiplicity and the Carnival of Difference: Curriculum Dilemmas in the Age of Postcolonialism and Globalization. In W. F. Pinar (Ed.), International Handbook of Curriculum Research (pp. 73-82). Mahwah, NJ \& London: Lawrence Erlbaum Associates, 
Publishers.

McGrath, J. E. (2004). Loving Big Brother: performance, privacy and surveillance space. London \& New York: Routledge.

Mitchell, W. J. T. (1994). Picture theory: Essays on verbal and visual representation. Chicago: University of Chicago Press.

Mitchell, W. J. T. (2002). Space, place, and landscape. In W. J. T. Mitchell (Ed.), Landscape and power (second ed.). Chicago: University of Chicago Press.

Moje, E. B. (2004). Powerful spaces: Tracing the out-of-school literacy spaces of Latino/a youth. In L. M. Leander \& M. Sheehy (Eds.), Spatializing literacy research and practice (pp. 15-38). New York: Peter Lang.

Naficy, H. (2001). An accented cinema: exilic and diasporic filmmaking. Princeton, N.J.:

Princeton University Press.

Ontario Arts Council: www.arts.on.ca

Pink, S. (2001). Doing Visual Ethnography: Images, Media and Representation in Research. London: Sage Publications.

Said, E. W. (1979). Orientalism. New York: Vintage Books.

Soja, E. W. (1996). Thirdspace: Journeys to Los Angeles and other real-and imaginedplaces. Malden: Blackwell Publishers.

Soja, E. W. (2004). Preface. In K. M. Leander \& M. Sheehy (Eds.), Spatializing literacy research and practice (pp. ix-xv). New York: Peter Lang.

Spivak, G. (1987). In other worlds: essays in cultural politics. New York: Methuen.

Stack, M., \& Kelly, D. M. (2006). Popular Media, Education and Resistance. Canadian Journal of Education, 29(1), 5-26. 
Trinh, T. M.-H. (1991). When the moon waxes red: representation, gender, and cultural politics. New York \& London: Routledge. 